\title{
Distribution and plant community associations of the understory bamboo Fargesia qinlingensis in the Foping National Nature Reserve, China
}

\author{
Xi-Chun Du • Yi Ren • Gao-Di Dang • Jeremy Lundholm
}

Received: 15 January 2011 / Accepted: 9 June 2011 / Published online: 1 July 2011

(C) INRA and Springer Science+Business Media B.V. 2011

\begin{abstract}
- Introduction Fargesia qinlingensis is the primary food source for the endangered giant panda during the summer months in the Qinling Mountains, but little is known about its spatial distribution and plant community associations.

- Methods and materials We examined the composition and structure of the forest canopy and topographic patterns as correlates of $F$. qinlingensis population structure in Foping National Nature Reserve (FNNR), Qinling Mountains, China.

- Discussion $F$. qinlingensis is the dominant understory vegetation from 1,800-2,600 $\mathrm{m}$ in FNNR. Populations of $F$. qinlingensis were associated with several different tree communities, mainly with broad-leafed dominants at intermediate elevations and conifers at higher elevations. F. qinlingensis was associated with herb communities of
\end{abstract}

Handling Editor: Gilbert Aussenac

X.-C. Du • Y. Ren $(\bowtie)$

College of Life Sciences, Shaanxi Normal University,

Xi'an 710062, People's Republic of China

e-mail: renyi@snnu.edu.cn

Y. Ren

e-mail: changan999@gmail.com

X.-C. Du

Xi'an University of Arts and Science,

Xi'an 710065, People's Republic of China

G.-D. Dang

Foping National Nature Reserve,

Foping County, Shaanxi Province 723400,

People's Republic of China

J. Lundholm

Biology Department/Environmental Studies Program,

Saint Mary's University,

Halifax, NS, Canada intermediate species richness. F. qinlingensis densities were lowest at the highest elevations in herb-rich alpine meadows and at low elevations where the most speciesrich tree communities had high cover.

- Conclusion The most species-rich tree and herb communities were not associated with $F$. qinlingensis populations, thus efforts to conserve both bamboo as a food resource for pandas and species diversity of other plants must prioritize the entire elevation range in these mountains.

Keywords Qinling mountain range - Vegetation .

Topography · Giant panda

\section{Introduction}

The forest canopy often influences the distribution and dominance of understory species, and plays a decisive role in the process of community development (Fredericksen et al. 1999; Gillet et al. 1999; McKenzie et al. 2000; Taylor et al. 2004). The distribution and dominance of understory plants may, in turn, affect long-term canopy structure and composition by influencing the establishment and growth of tree species seedling populations (George and Bazzaz 1999), especially in bamboo forests (Narukawa and Yamamoto 2002; Taylor et al. 2004; Wang et al. 2006).

Bamboo species form the dominant understory vegetation of the giant panda (Ailuropoda melanoleuca) habitat in China (Hu et al. 1985; Taylor et al. 2004). While the distribution and abundance of these understory bamboo species are influenced by the forest canopy (Taylor et al. 2004), in turn, they also affect canopy structure and composition (Wang et al. 2006). At the same time, understory bamboo species influence the distributions of other understory plant species (Linderman et al. 2004) and 
wild animal species (Wei et al. 1999), including the giant panda, and knowledge of bamboo distribution can help map the spatial distribution of animal species. Understory bamboo makes up $99 \%$ diet of the wild giant panda is bamboo (Hu et al. 1985) and its distribution and ecological relationships to other plant species are essential for giant panda conservation (Taylor et al. 2004; Wang et al. 2006).

Most research on giant panda and its habitat was originally conducted in Sichuan province of China (Hu et al. 1985; Schaller et al. 1985; Taylor et al. 1991; Liu et al. 1999; Taylor and Qin 1988). More attention has been paid recently to panda populations in the Qinling Mountains (Yang et al. 1998; Wang et al. 2006). According to the latest survey, the giant panda reaches its highest density in Foping National Nature Reserve (FNNR) in the Qinling Mountains (State Forestry Administration 2006), where a bamboo species, Fargesia qinlingensis, which dominates the understory of subalpine forests, makes up the pandas only food resource during summer (Yang et al. 1998; Wang et al. 2006). Therefore, research on habitat preferences and plant community associations of $F$. qinlingensis has special significance for panda conservation at Qinling Mountains (Yang et al. 1998; Ren 1998; Wang et al. 2006). F. qinlingensis is the dominant understory bamboo species in subalpine forests at FNNR (Ren 1998), but the distribution of this understory bamboos is patchy, thus habitat models including distribution and abundance of $F$. qinlingensis show much smaller estimates than expected of suitable panda habitat area in nature reserves (Linderman et al. 2005). Predicting the spatial distribution of bamboo species at a fine scale has not been possible due to the lack of any significant relationship between overstory and abiotic variables and the presence or absence of bamboo (Linderman et al. 2004).

The goal of this study was to better understand the implications of the bamboo species $F$. qinlingensis for the giant panda's habitat. To achieve this aim, we surveyed the distribution and abundance of $F$. qinlingensis, the plant species composition and structure of the forest, and topographic characteristics in FNNR.

\section{Methods and materials}

\subsection{Study site}

The study was conducted in the FNNR, which is located on the south slope of the Qinling Mountains, Shaanxi Province, China $\left(107^{\circ} 40^{\prime}-107^{\circ} 55^{\prime} \mathrm{E}, 33^{\circ} 33^{\prime}-33^{\circ} 46^{\prime} \mathrm{N}\right)$. The reserve spans the north subtropical and temperate zones, with a warm, humid climate. With elevations ranging from $980-2,900 \mathrm{~m}$, there are several climatic zones in the reserve, and consequently it has high habitat diversity. From the lowest elevation to approximately $2,000 \mathrm{~m}$, the canopy consists mainly of deciduous broad-leaved Quercus species. From 2,000 to $2,500 \mathrm{~m}$, there is mixed coniferous and deciduous broadleaf forest with Betula and Abies as dominant species. The canopy is dominated by coniferous forest consisting of Abies fargesii from 2,500-2,800 $\mathrm{m}$ (Ren 1998). Throughout the reserve, forest canopies average $56 \%$ closure and rarely exceed $90 \%$, maintaining significant gap areas that allow light penetration. According to the third-level survey on panda population and habitat, the highest giant panda density in China occurs in this reserve (State Forestry Administration 2006). The vegetation is diverse due to the coexistence of both northern and southern Chinese taxa (Pan et al. 1988; Ren 1998). At present, there are 1,377 species of seed plants, belonging to 561 genera and 132 families, respectively (Ren 1998).

\subsection{Field methods}

The reserve was divided into three sections, each including a mountain peak (to facilitate placement of vertical transects): Lubanzhai (2,904 m), Guangtoushan (2,800 m), and Sangebao (2,500 m; Ren 1998). A vertical transect was set from the highest point to the lowest point in each of the sections, more or less heading south. Along the transect from the Lubanzhai peak (which contained the greatest elevation gradient), every $150 \mathrm{~m}$, a study stand with two $20 \times 20-\mathrm{m}$ plots was established, and every $300 \mathrm{~m}$ along the other two transects. The distance between the two plots within a stand was $30 \mathrm{~m}$. Because of a localized hailstorm which destroyed foliage in one area, only one plot was established at the $2,300 \mathrm{~m}$ in elevation on the first transect, so 15 plots were sampled along the first transect from $1820 \mathrm{~m}$ to $2,900 \mathrm{~m}$. There were eight plots along the second transect from 1,900 to $2,800 \mathrm{~m}$, and 10 plots along the third transect from 1,760 to $2,615 \mathrm{~m}$, for 33 plots total in the survey from July to September 2002. Altitude, aspect and slope were recorded for each plot.

The southwestern corner of each $20 \times 20$-m tree plot were used as a starting point from which the position and diameter at breast height (DBH) of each individual tree $>5 \mathrm{~cm}$ was quantified $(x$ axis $=$ eastern direction; $y$ axis $=$ northern direction). After estimating the height, projection diameter, and the height of the lowest branch of each individual tree $>5 \mathrm{~cm}$ from about $3 \mathrm{~m}$ away, we plotted every individual tree on the graph paper according to their position and projection diameter, so we could calculate the cover area of each individual tree, and summed for the plot as total projection area; overlap was the total projection area divided by percent cover.

Tree architecture is an important determinant of the height extension and light capture (David 1998; Lourens et al. 2006); it allows species to exploit the vertical height gradient in the forest canopy and horizontal light gradients at the forest floor. Lowest branch height is used here as an index of light availability at the forest floor: higher lowest 
branch heights are associated with thinner tree canopies (Wei et al. 1999) that allow greater light penetration, plots with no trees were given values of $15 \mathrm{~m}$ and $10 \mathrm{~m}$ for lowest and average lowest branch height, respectively (to reflect relatively high light penetrations), so that these plots could be included in the analyses. Stem area at breast height of each individual tree was calculated from its DBH, and summed to calculate stem area at breast height for each plot. These stand variables represent various indicators of forest biomass or light penetration that may be related to bamboo population characteristics.

Five $1 \times 1-\mathrm{m}$ plots (four at the corner, one at the center) in every $20 \times 20$-m plot were set to investigate the abundance and distribution of $F$. qinlingensis and herbaceous species. In each of the $1 \times 1-\mathrm{m}$ herb species plot, each individual herb was identified and counted, so herb density (stems $/ 5 \mathrm{~m}^{2}$ ) and diversity can be calculated. The abundance and distribution of $F$. qinlingensis in every $1 \times 1-\mathrm{m}$ plot was also surveyed. Culms of $F$. qinlingensis were divided into new shoots (dark green, sheaths still attached to the nodes), culms more than 1 year old (light green, sheaths fallen out from the nodes; Wang et al. 2006), and dead culms. We counted all the culms, and measured their heights. Then the distribution of $F$. qinlingensis in the plot was plotted on graph paper, and the percent cover of bamboo plots calculated.

\subsection{Data analysis}

In order to determine the relationships between potential univariate predictors and response variables, redundancy in both predictor (forest structure, species diversity, topographic variables) and response variables (bamboo) was reduced using principal components analysis (PCA). This reduced the number of potential predictors from 20 to five. In order for aspect to be used in linear methods, it was first transformed to northness and eastness using the cosine and sine, respectively, of the radian angle. The response variables related to bamboo density and bamboo cover were also subjected to PCA; this resulted in a single principal component with eigenvalue $>1$, but the loadings were below 0.3 for all variables, thus we ended up using univariate correlation analyses (Pearson's) to explore the relationships among bamboo variables (only plots containing bamboo were used for the correlation analyses). We ended up selecting total number of stems, average height, and total number of new stems as the key bamboo response variables for subsequent analyses, since total number of stems (total density) was positively correlated with all other density variables, height was related to none of the other variables and is likely correlated with overall bamboo productivity (Qin et al. 1993), and new shoot density is likely most important to giant pandas as a food resource. To explore the relationships between bamboo variables and predictors, multiple linear regression with backward and forward stepwise selection using stepAIC in R (v. 2.8.1) were carried out between each of the three bamboo variables and the set of five principal components.

To examine the relationships between community composition and bamboo characteristics, we used detrended correspondence analysis (DCA) for tree and herb communities separately since these were sampled at different scales. Both non-metric multidimensional scaling and DCA were attempted, and results were similar. We present only DCA results here because the DCA produces a unique solution and is easier to interpret in terms of environmental gradients. The abundance measure for both was density (for trees: total number of stems of each species in each $20 \times 20-\mathrm{m}$ plot; for herbs: total number of stems summed over all five sub-plots within each $20 \times 20$-m plot). Two plots that contained only Larix chinensis in the tree layer were omitted from the tree ordination as they were extreme outliers on the ordination plots. For the herb plots, bamboo density was included with the other species in the ordination. We used an indirect gradient analysis to examine the relationships between aspect (transformed as described above), slope, elevation, and community structure (ENVFIT function in vegan, R-package v. 2.8.1). We opted for an indirect approach, as without prior knowledge of appropriate constraints, direct gradient analysis is not advisable (Oksanen 2008). To determine the relationships between community composition and other structural variables, for both herb and tree ordinations, we used tree species richness, total DBH, and tree cover, as well as herb species richness as environmental variables in the indirect gradient analysis. To determine the forest community composition most closely associated with bamboo population abundance, bamboo total density, new culm density and average height were also used as "environmental variables" in the indirect gradient analysis of the tree communities. Since giant pandas prefer areas with intermediate densities of bamboo culms, we indicated plots with between 25 and $50 \mathrm{culms} / \mathrm{m}^{2}$ (Wang et al. 2007) with separate symbols on the ordination diagrams.

\section{Results}

\subsection{F. qinlingensis distribution and abundance}

Understorey bamboo (F. qinlingensis) occurred from 1,760 $2,800 \mathrm{~m}$, and had $>85 \%$ cover between 1,800 and $2,600 \mathrm{~m}$. Cover dropped to below $10 \%$ above $2,800 \mathrm{~m}$ in the subalpine shrub and meadow areas. Below $1,800 \mathrm{~m}$, in the deciduous broad-leaved forest areas, $F$. qinlingensis was uncommon, with cover below $1 \%$ in some plots (Table 1). The average density was $28.9 \mathrm{culms} / \mathrm{m}^{2}$, with density reaching a maximum of $49.7 \mathrm{culms} / \mathrm{m}^{2}$ at $2450 \mathrm{~m}$ in 
Table $1 F$. qinlingensis and topographical factors in the 20 study plots

\begin{tabular}{|c|c|c|c|c|c|c|c|c|c|}
\hline Plot & Aspect & Slope & Elevation & $\begin{array}{l}\text { Area of } \\
\text { bamboo }\end{array}$ & $\begin{array}{l}\text { New } \\
\text { culms } / 5 \mathrm{~m}^{2}\end{array}$ & $\begin{array}{l}\text { Dead } \\
\text { culms } / 5 \mathrm{~m}^{2}\end{array}$ & $\begin{array}{l}\text { Living } \\
\text { culms } / 5 \mathrm{~m}^{2}\end{array}$ & $\begin{array}{l}\text { Total } \\
\text { culms } / 5 \mathrm{~m}^{2}\end{array}$ & $\begin{array}{l}\text { Average } \\
\text { height }\end{array}$ \\
\hline F1-1-1 & $\mathrm{E}$ & 10 & 2,900 & 0 & 0 & 0 & 0 & 0 & \\
\hline F1-1-2 & $\mathrm{E}$ & 10 & 2,890 & 0 & 0 & 0 & 0 & 0 & \\
\hline F1-2-1 & SW & 20 & 2,746 & 0 & 0 & 0 & 0 & 0 & \\
\hline F1-2-2 & SW & 20 & 2,720 & 0 & 0 & 0 & 0 & 0 & \\
\hline F1-3-1 & SE & 25 & 2,600 & 379.5 & 27 & 29 & 217 & 273 & 1.24 \\
\hline F1-3-2 & SW & 25 & 2,600 & 363.5 & 36 & 35 & 203 & 274 & 1.13 \\
\hline F1-4-1 & $\mathrm{S}$ & 30 & 2,420 & 392.5 & 29 & 33 & 158 & 220 & 1.76 \\
\hline F1-4-2 & SE & 35 & 2,450 & 369.5 & 39 & 45 & 261 & 345 & 1.36 \\
\hline F1-5-1 & $\mathrm{NE}$ & 35 & 2,300 & 377.4 & 19 & 14 & 122 & 155 & 1.51 \\
\hline F1-6-1 & SE & 30 & 2,150 & 395.8 & 12 & 24 & 153 & 189 & 1.8 \\
\hline F1-6-2 & SE & 30 & 2,160 & 397.4 & 15 & 24 & 148 & 187 & 1.88 \\
\hline F1-7-1 & W & 30 & 2,000 & 0 & 0 & 0 & 0 & 0 & \\
\hline F1-7-2 & $\mathrm{N}$ & 35 & 1,970 & 0 & 0 & 0 & 0 & 0 & \\
\hline F1-8-1 & W & 35 & 1,850 & 0 & 0 & 0 & 0 & 0 & \\
\hline F1-8-2 & Sw & 35 & 1,820 & 0 & 0 & 0 & 0 & 0 & \\
\hline F2-1-1 & $\mathrm{S}$ & 15 & 2,800 & 0 & 0 & 0 & 0 & 0 & \\
\hline F2-1-2 & SW & 25 & 2,827 & 0 & 0 & 0 & 0 & 0 & \\
\hline F2-2-1 & SW & 20 & 2,500 & 375 & 36 & 20 & 126 & 182 & 2.3 \\
\hline F2-2-2 & SW & 25 & 2,500 & 113.2 & 13 & 32 & 69 & 114 & 1.99 \\
\hline F2-3-1 & SE & 20 & 2,200 & 368 & 23 & 33 & 114 & 170 & 2.45 \\
\hline F2-3-2 & NW & 30 & 2,200 & 372.8 & 16 & 26 & 45 & 87 & 1.74 \\
\hline F2-4-1 & SW & 30 & 1,900 & 0 & 0 & 0 & 0 & 0 & \\
\hline F2-4-2 & NW & 30 & 1,890 & 0 & 0 & 0 & 0 & 0 & \\
\hline F3-1-1 & SW & 5 & 2,630 & 357.7 & 13 & 57 & 182 & 252 & 1.59 \\
\hline F3-1-2 & SE & 30 & 2,630 & 0 & 0 & 0 & 0 & 0 & \\
\hline F3-2-1 & SW & 20 & 2,350 & 385.5 & 8 & 23 & 100 & 131 & 1.35 \\
\hline F3-2-2 & $\mathrm{S}$ & 40 & 2,350 & 388 & 22 & 28 & 102 & 152 & 1.57 \\
\hline F3-3-1 & $\mathrm{S}$ & 5 & 1,900 & 355.8 & 6 & 4 & 70 & 80 & 1.32 \\
\hline F3-3-2 & $\mathrm{S}$ & 5 & 1,920 & 326.4 & 11 & 14 & 140 & 165 & 1.05 \\
\hline F3-3a-1 & W & 35 & 2,040 & 273.6 & 10 & 0 & 91 & 101 & 1.05 \\
\hline F3-3a-2 & W & 35 & 2,050 & 300.7 & 10 & 4 & 155 & 169 & 1.32 \\
\hline F3-5-1 & $\mathrm{S}$ & 5 & 1,760 & 21.6 & 4 & 14 & 25 & 43 & 2.45 \\
\hline F3-5-2 & $\mathrm{S}$ & 5 & 1,760 & 0 & 0 & 0 & 0 & 0 & 0 \\
\hline
\end{tabular}

elevation. At 2,800 m elevation, the density of $F$. qinlingensis was 13.2 culms $/ \mathrm{m}^{2}$, less than half of the average level; at the altitude of $1,760 \mathrm{~m}$, density was only $3.9 \mathrm{culm} / \mathrm{m}^{2}$, only oneeighth of the average density (Table 1).

With declining elevation, the number of new culms and dead culms decreased, thus the turnover rate of $F$. qinlingensis slowed down. The highest average density of new bamboo shoots was $6.4 \mathrm{culms} / \mathrm{m}^{2}$, between 2,200 and $2,600 \mathrm{~m}$. With declining elevation, the average height of adult $F$. qinlingensis culms increased slightly (Table 1). Average height of bamboo was $1.6 \pm 0.43 \mathrm{~m}$. Although the density of $F$. qinlingensis was the lowest at the $1,760 \mathrm{~m}$ in elevation, the height was $2.5 \mathrm{~m}$, which was the highest in all the plots. Average height was less than $1 \mathrm{~m}$ at the highest elevation of 2,800 (Table 1).

There were significant positive correlations between bamboo cover and new shoot density and total culm density (Table 2). So areas with greater bamboo cover had greater overall density and new shoots. New shoot density was postively correlated with dead, living, and total culm density. Average height of bamboo culms was not correlated with the other variables (Table 2).

Principal components analysis returned five PCs with eigenvalues $>1$ for the environmental and forest structure variables, accounting for $84 \%$ percent of the total variance (Table 3 ). The first PC was negatively related to variables 
Table 2 Pairwise correlation coefficients comparing $F$. qinlingensis population structure

\begin{tabular}{lllllll}
\hline & $\begin{array}{l}\text { Bamboo } \\
\text { cover }\end{array}$ & $\begin{array}{l}\text { New shoot } \\
\text { density }\end{array}$ & $\begin{array}{l}\text { Dead culm } \\
\text { density }\end{array}$ & $\begin{array}{l}\text { Living culm } \\
\text { density }\end{array}$ & $\begin{array}{l}\text { Total culm } \\
\text { density }\end{array}$ & $\begin{array}{l}\text { Average } \\
\text { height }\end{array}$ \\
\hline Bamboo cover & 1 & $0.542^{*}$ & 0.386 & $0.589^{* *}$ & $0.508^{*}$ & 0.19 \\
New shoot density & $0.542^{*}$ & 1 & $0.568^{* *}$ & $0.672^{* *}$ & $0.747^{* *}$ & 0.253 \\
Dead culm density & 0.386 & $0.568^{* *}$ & 1 & $0.550^{*}$ & $0.659^{* *}$ & 0.361 \\
Living culm density & $0.589^{* *}$ & $0.672^{* *}$ & $0.550^{*}$ & 1 & $0.976^{* *}$ & 0.003 \\
Total culm density & $0.508^{*}$ & $0.747^{* *}$ & $0.0 .659^{* *}$ & $0.976^{* *}$ & 1 & -0.282 \\
Average height & 0.19 & 0.253 & 0.361 & 0.003 & -0.282 & 1 \\
\hline
\end{tabular}

$* P<0.05 ; * * P<0.01$

by low slopes, southern aspect, low tree richness, high ratio of dead to living trees, and taller trees with lower branch heights. The results for eastness are contradictory, i.e., density is positively related to PCs variously negatively and positively related to the eastern aspect; univariate correlations between eastness and total density were not significant. New shoot density was positively related to PC3, thus more new shoots were found in areas characterized by most of the same features as total density. Average height was positively related to $\mathrm{PC} 3$ and $\mathrm{PC} 5$, similar to total density.

\subsection{Composition and structure of the forest canopy}

The average number of species (trees and herbs combined) was $31.15 \pm 8.37$ (SD) in the 33 plots; highest at $2,900 \mathrm{~m}$ in elevation (61 species); lowest at $2,150 \mathrm{~m}$ in elevation (13
Table 3 Principal components summarizing environmental and forest structural variables

\footnotetext{
${ }^{a}$ See methods for details of environmental variables
}

\begin{tabular}{|c|c|c|c|c|c|}
\hline & $\mathrm{PC} 1$ & $\mathrm{PC} 2$ & PC3 & PC4 & PC5 \\
\hline Standard deviation & 3.08 & 1.53 & 1.45 & 1.21 & 1.11 \\
\hline Proportion of total & 0.48 & 0.12 & 0.11 & 0.07 & 0.06 \\
\hline \multicolumn{6}{|l|}{ Variance explained } \\
\hline Eastness $^{\mathrm{a}}$ & -0.02 & -0.09 & 0.34 & 0.11 & -0.57 \\
\hline Northness & -0.07 & 0.20 & -0.28 & -0.38 & -0.38 \\
\hline Slope & -0.01 & 0.45 & 0.00 & -0.11 & -0.48 \\
\hline Elevation & 0.29 & -0.11 & 0.20 & -0.09 & -0.02 \\
\hline Total richness & 0.10 & -0.53 & 0.09 & -0.03 & -0.24 \\
\hline Tree richness & -0.26 & -0.11 & -0.28 & -0.04 & 0.05 \\
\hline Herb richness & 0.21 & -0.39 & 0.19 & -0.01 & -0.19 \\
\hline Tree density & -0.26 & -0.24 & -0.17 & -0.16 & -0.17 \\
\hline Dead tree density & -0.19 & -0.09 & 0.17 & -0.43 & -0.00 \\
\hline Dead/living tree density & -0.04 & 0.18 & 0.49 & -0.24 & 0.26 \\
\hline Tree average height & -0.22 & 0.24 & 0.29 & 0.14 & -0.02 \\
\hline Tree maximum height & -0.28 & 0.17 & 0.16 & 0.08 & -0.13 \\
\hline Lowest branch height & 0.26 & 0.12 & -0.18 & 0.25 & -0.07 \\
\hline Average lowest branch height & 0.19 & 0.13 & -0.29 & 0.32 & -0.14 \\
\hline Maximum DBH & -0.24 & 0.06 & 0.20 & 0.36 & 0.01 \\
\hline Stem area & -0.23 & -0.10 & 0.13 & 0.45 & -0.14 \\
\hline Maximum projection diameter & -0.29 & -0.00 & -0.02 & -0.04 & 0.05 \\
\hline Tree cover & -0.30 & -0.11 & -0.12 & -0.05 & -0.14 \\
\hline Projected area & -0.28 & -0.18 & -0.20 & 0.12 & 0.04 \\
\hline Overlap & -0.29 & -0.13 & -0.03 & 0.07 & 0.14 \\
\hline
\end{tabular}


Table 4 Multiple regression of environmental variable principal components on bamboo density

\begin{tabular}{|c|c|c|c|c|}
\hline & Estimate & Std. error & $t$ value & $P$ \\
\hline \multicolumn{5}{|c|}{ Bamboo total density } \\
\hline \multicolumn{5}{|c|}{$F_{3,29}=6.88, R^{2}$ adj $=0.35, P=0.001$} \\
\hline (Intercept) & 99.667 & 14.501 & 6.873 & $1.5 \mathrm{e}-07 * * *$ \\
\hline PC2 & 14.543 & 9.611 & 1.513 & 0.141054 \\
\hline $\mathrm{PC} 3$ & 38.008 & 10.133 & 3.751 & $0.000783 * * *$ \\
\hline PC5 & 27.484 & 13.267 & 2.072 & $0.047299 *$ \\
\hline \multicolumn{5}{|c|}{ Bamboo new shoot density } \\
\hline \multicolumn{5}{|c|}{$F_{2,30}=7.22, R^{2}$ adj $=0.28, P=0.002$} \\
\hline (Intercept) & 10.576 & 1.803 & 5.866 & $2.03 \mathrm{e}-06 * * *$ \\
\hline $\mathrm{PC} 2$ & 1.982 & 1.195 & 1.659 & 0.10762 \\
\hline PC3 & 4.306 & 1.260 & 3.418 & $0.00183 * *$ \\
\hline \multicolumn{5}{|c|}{ Bamboo height } \\
\hline \multicolumn{5}{|c|}{$F_{2,30}=4.461, R^{2}$ adj $=0.18, P=0.02$} \\
\hline (Intercept) & 0.93515 & 0.13880 & 6.737 & $1.81 \mathrm{e}^{-07}$ \\
\hline PC3 & 0.20718 & 0.09699 & 2.136 & 0.0409 \\
\hline PC5 & 0.26515 & 0.12699 & 2.088 & 0.0454 \\
\hline
\end{tabular}

species). With increasing elevation, the number of tree species declined while herbaceous species increased, thus, there was no overall trend in total species richness. The average number of tree species was $5.09 \pm 4.63$ in the quadrats; there were no tree species at $2,800 \mathrm{~m}$ sub alpine shrub and meadow regions; tree species richness reached a maximum of 15 at $1,920 \mathrm{~m}$; in general, there were more tree species below $2,000 \mathrm{~m}$. There were large differences in herb richness among plots; there were 61 species of herbs at $2,900 \mathrm{~m}$ in elevation, which was also the highest in the reserve (Appendix Table 5).

With increasing elevation, the number of tree species, tree density, coverage, overlap, and areal projection declined, representing an overall decrease in forest dominance over the elevation gradient. Plots had the most trees at $2,050 \mathrm{~m}$ in elevation, 39 individual trees are more than $5 \mathrm{~cm}$ in DBH. No individual tree was in the quadrats at 2,800 $\mathrm{m}$ in elevation, where $F$. qinlingensis had its maximum abundance along the elevation gradient (Appendix Table 5). On average, there were $17.35 \pm 9.82$ tree stems per plot.

Ordination and fitting of environmental variables to tree species abundance patterns shows that the main gradient of species composition (DCA1) is an elevation gradient (Fig. 1), with many more species and high cover associated with lower elevations; these are mainly deciduous broadleaved species such as Betula chinensis, Quercus aliena, and Cyclobalanopsis gracilis. F. qinlingensis height and density (both new and total), however, are associated with higher elevations, lower slopes, southern aspects, and different community composition with species such as $A$. fargesii, Sabina squamata, Sorbus koehneana, Populus davidii, and Pinus armandii. Another set of species not associated with high densities of bamboo was found on higher slopes with north and eastern exposure and was dominated by Ulmus propinqua, Staphylea bumalda, Tsuga chinensis, and Acer grosseri. Plots with intermediate bamboo densities are found in a range of tree communities across a fairly broad portion of the elevation gradient including conifers such as $A$. fargesii and broad-leaved species such as Betula albo-sinensis var. septentrionalis, Acer robustum, and Rhododendron hypoglaucum, but not at the extremes of elevation (Fig. 1). Herb species composition ordinations show that $F$. qinlingensis is associated with intermediate elevations, intermediate tree, and total species

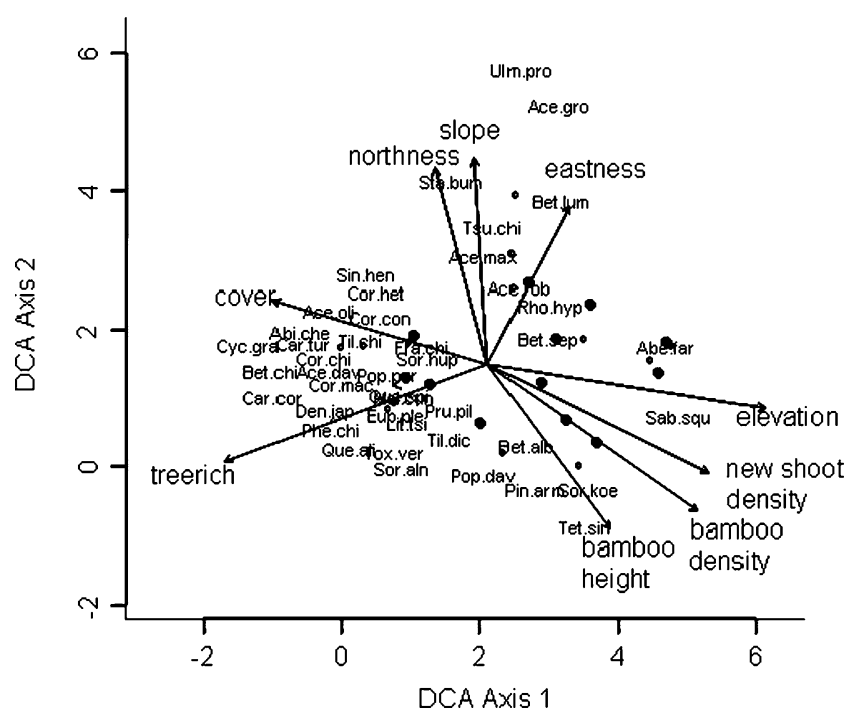

Fig. 1 Ordination of tree species composition with fitted environmental variables (eigenvalues: Axis $1=0.75$; Axis $2=0.62$ ). Species names represent centroids of species abundance (some were moved slightly for legibility); arrows indicate environmental variables selected by the ENVFIT procedure with $P<0.05$ : see text for details on environmental variables (arrow length multiplied by 5 for visibility). Solid circles are plots with between 25 and 50 living bamboo culms $/ \mathrm{m}^{2}$. Other plots are represented by hollow circles. nomenclature follows (Ren 1998): Abi.far Abies fargesii, Abi.che Abies chensiensis, Ace.dav Acer davidii, Ace.gro Acer grosseri, Ace. max Acer maximowiczii, Ace.oli Acer oliverianum, Ace.rob Acer robustum, Bet.alb Betula albo-sinensis, Bet.chi Betula chinensis, Bet. lum Betula luminifera, Bet.sep Betula albo-sinensis var. septentrionalis, Car.cor Carpinus cordata, Cartur Carpinus turczaninowii, Cor.chi Corylus chinensis, Cor.con Cornus controversa, Cor.het Corylus heterophylla, Cormac Cornus macrophylla, Cyc.gra Cyclobalanopsis gracilis, Den.jap Dendrobenthamia japonica var. chinensis, Eup.ple Euptelea pleiosperma, Fra.chi Fraxinus chinensis, Lit.tsi Litsea tsinlingensis, Mel.cun Meliosma cuneifolia, Phe.chi Phellodendron chinense, Pin.arm Pinus armandii, Pop.dav Populus davidiana, Pop. pur Populus purdomii, Pru.pil Prunus pilosiuscula, Que.ali Quercus aliena var. acuteserrata, Que.spi Quercus spinosa, Rho.hyp Rhododendron hypoglaucum, Sab.squ Sabina squamata var. fargesii, Sin.hen Sinowilsonia henryi, Sor.aln Sorbus alnifolia, Sor.hup Sorbus hupehensis, Sorkoe Sorbus koehneana, Sta.bum Staphylea bumalda, Tet.sin Tetracentron sinensis, Til.chi Tilia chinensis, Til.dic Tilia dictyoneura, Tox.ver Toxicodendron vernicifluum, Tsu.chi Tsuga chinensis, Ulm.pro Ulmus propinqua 
richness and herb species such as Carpesium macrocephalum, Polygonum amplexicaule, and Carex tangiana (Fig. 2). More species-rich herb communities were found at higher elevations and included Acorus gramineus, Cerastium arvense, Corydalis curviflora, and Cacalia auriculata. More species poor communities containing Dioscorea zingiberensis, Viola

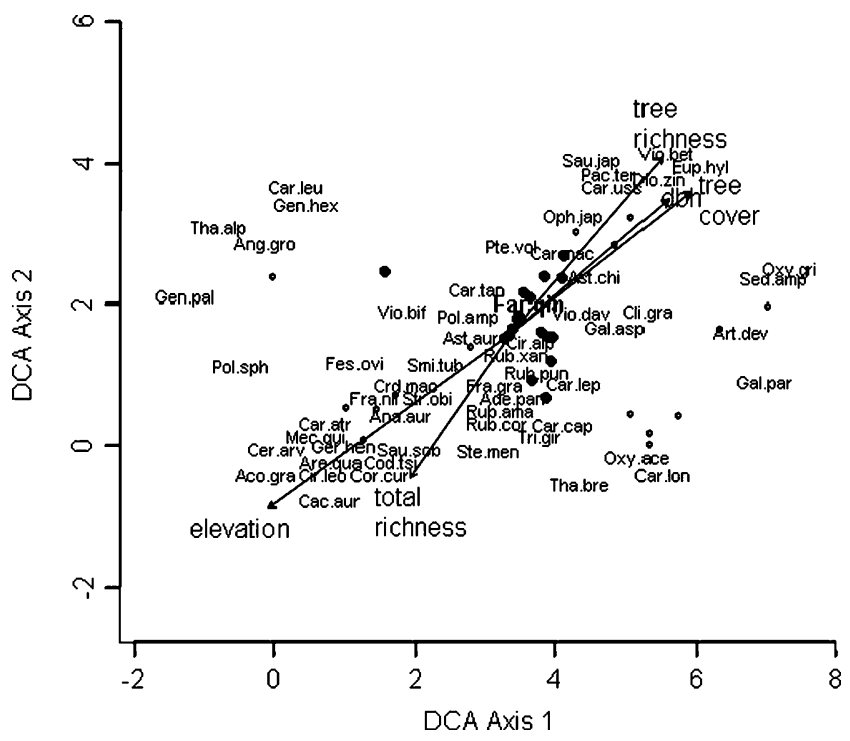

Fig. 2 Ordination of herb species and $F$. qinlingensis with fitted environmental variables (eigenvalues: Axis $1=0.69$; Axis $2=0.43$ ). Species names represent centroids of species abundance (some were moved slightly for legibility); arrows indicate environmental variables selected by the ENVFIT procedure with $P<0.05$ : see text for details on environmental variables (arrow length multiplied by 5 for visibility). Solid circles are plots with between 25 and 50 living bamboo culms $/ \mathrm{m}^{2}$. Other plots are represented by hollow circles. Nomenclature follows (Ren 1998): Aco.gra Acorus gramineus, Ade. pan Adenophora paniculata, Ana.aur Anaphalis aureopunctata, Ang. gro Angelica grosseserrata, Are.qua Arenaria quadridentata, Art.dev Artemisia deversa, Ast.aur Aster auriculatus, Ast.chi Astilbe chinensis, Cac.aur Cacalia auriculata, Car.atr Carex atrofusca, Car.cap Carex capilliformis, Car.lep Carpesium leptophyllum, Car.leu Carex leucochlora, Car.lon Carex longerostrata var. tsinlingensis, Car.mac Carpesium macrocephalum, Cartan Carex tangiana, Car.uss Carex ussuriensis, Cer.arv Cerastium arvense, Cir.alp Circaea alpina, Cir.leo Cirsium leo, Cli.gra Clinopodium gracile, Cod.tsi Codonnopsis tsinlingensis, Cor.cur Corydalis curviflora, Crd.mac Cardamine macrophylla, Dio.zin Dioscorea zingiberensis, Eup.hyl Euphorbia hylonoma, Far.qin Fargesia qinlingenses, Fes.ovi Festuca ovina, Fra.gra Fragaria gracilis, Fra.nil Fragaria nilgerrensis, Gal.asp Galum asperuloides var. hoffmeisteri, Gal.par Galium paradoxum, Gen.hex Gentiana hexaphylla var. pentaphylla, Gen.pal Gentianopsis paludosa, Ger.hen Geranium henyi, Mec.qui Meconopsis quintuplinervia, Oph.jap Ohiopogon japonicus, Oxy.ace Oxylis acetosella, Oxy. gri Oxylis griithii, Pac.ter Pachysandra terminalis, Pol.amp Polygonum amplexicaule var. sinense, Pol.sph Polygonum sphaerostachyum, Pte.vol Pterygocalyx volubilis, Rub.ama Rubus amabilis, Rub.cor Rubus corchroriolius, Rub.pun Rubus pungens var. indeensus, Rub.xan Rubus xanthocarpus, Sau.jap Saussurea japonica, Sau.sob Saussurea sobarocephala, Sed.amp Sedum amplibracteatum, Smi.tub Smilacina tubiera, Ste.men Stellaria menorum, Strobi Streptopus obiusatus, Tha. alp Thalictrum alpinum var. elatum, Tha.bre Thalictrum brevisericeum, Tri.gir Trigonotis giraldii, Vio.bet Viola betoniciolia subsp. nepalensis, Vio.bif Viola biflora, Vio.dav Viola davidii betoniciolia, and Pachysandra terminalis were found at lower elevations associated with greater tree cover and richness, and the deciduous forest tree species described above. Plots with intermediate bamboo densities were found in herb communities of intermediate richness.

\section{Discussion}

\subsection{Distribution and abundance of $F$. qinlingensis}

Pandas typically select areas with gentle slopes (Wei et al. 1996; Zhang et al. 2004, 2006), presumably, this saves energy in movement (Schaller et al. 1985). Pandas typically select areas with intermediate densities for some bamboo species (Zhang et al. 2002). Where bamboo is too scarce, pandas have to spend too much time and energy to find food, but if culm density is too high, movement is restricted, and nutritional quality may also be lower (Zhang and Hu 2000). Intermediate levels of bamboo density were found over a broad range of communities along the elevation gradient, in areas with intermediate to low tree cover at FNNR. In the spring, giant pandas eat bamboo shoots with high moisture content and can be more easily digested and absorbed compared with older tissues, thus bamboo shoot density may be an important predictor of giant panda habitat suitability ( $\mathrm{Hu}$ et al. 1994). According to this study, new shoot densities of $F$. qinlingensis were related to several other density variables, and thus overall density may be a fairly good predictor of panda food resources, with the caveat that intermediate densities of $F$. qinlingensis are preferred by pandas. Since dead and new culm densities were positively correlated, there is no evidence here of population decline, indeed most plots had greater densities of new shoots than dead shoots, suggesting that populations may be stable (Wang et al. 2007), although further research is necessary to support this idea. In this study, bamboo heights were greatest in forest communities comprised of Pinus armandii, Tetracentron sinensis, and S. koehneana, typically also the areas with greatest bamboo densities.

\subsection{Plant community associations}

This study shows that $F$. qinlingensis populations in FNNR are not associated with a single plant community but have broad overlap with several different plant communities. Likewise, F. qinlingensis abundance was lowest at the elevation extremes but generally consistent across a wide elevational range. In general, bamboos have high soil moisture requirements (Kleinhenz et al. 2003) and prefer wet environments such as tropical and subtropical forests. We can infer from these studies on other bamboo species that high soil moisture and generally wetter conditions are 
important for the growth and development of $F$. qinlingensis. This likely explains the vertical limit of $F$. qinlingensis in FNNR: due to the long dry northern wind, high elevations contain only A. fargesii, S. squamata, and L. chinensis in terms of woody plants (Ren 1998). At lower elevations, bamboo may be facilitated by conifers that have relatively low canopy cover due to low leaf area indices such as $A$. fargesii, providing partial shade in the summer. Disturbance due to conifer logging negatively influenced the survivorship of dwarf bamboo ( $\mathrm{Li}$ and Denich 2001), possibly because of the sheltering effect of conifers. This condition was similar in Sichuan province where pandas prefer forests with higher canopy coverage, for young pandas climb trees to avoid enemies, and mostly give birth in tree cavities. Light conditions under the canopy in the leafless season can have a great effect on bamboo biomass (Toko et al. 2005). At the lower elevations where tree canopy cover is higher, light availability likely limits the density of $F$. qinlingensis.

In areas where bamboo is dominant, it has been suggested that tree species richness can be low because bamboos reduce tree regeneration (Taylor and Qin 1988). In conclusion, conditions of low temperature and desiccation may limit the upper part of its elevation range while light may be limiting at the lower end of its range. High species richness tree communities at low elevations and high richness herb communities at high elevations were not associated with $F$. qinlingensis populations in FNNR, thus efforts to conserve both bamboo as a food resource for pandas and species diversity of other plants must prioritize the entire elevation range in these mountains.

\subsection{Implications for giant panda habitat}

As the dominant species of the understory subalpine forests and the panda's only food resource during summer in FNNR at the Qinling Mountains, F. qinlingensis has a wide tolerance of environmental conditions and is found in a variety of plant communities. Intermediate density level of F. qinlingensis were found over a broad range of communities along the elevation gradient, in areas with intermediate to low tree cover, especially in coniferous forests dominated by $A$. fargesii and mid-elevation broad-leaved forests. This may partly account for the fact that the giant panda reaches its highest density in FNNR at the Qinling Mountains (State Forestry Administration 2006). The spatial distribution and abundance of $F$. qinlingensis within different plant communities quantified here provides important baseline ecological information regarding panda habitat in the Qinling Mountains, and sets up future studies of habitat use by pandas in the region.

Acknowledgment The subject was supported by The State Key Basic Research and Development Plan of China (G20004680001).

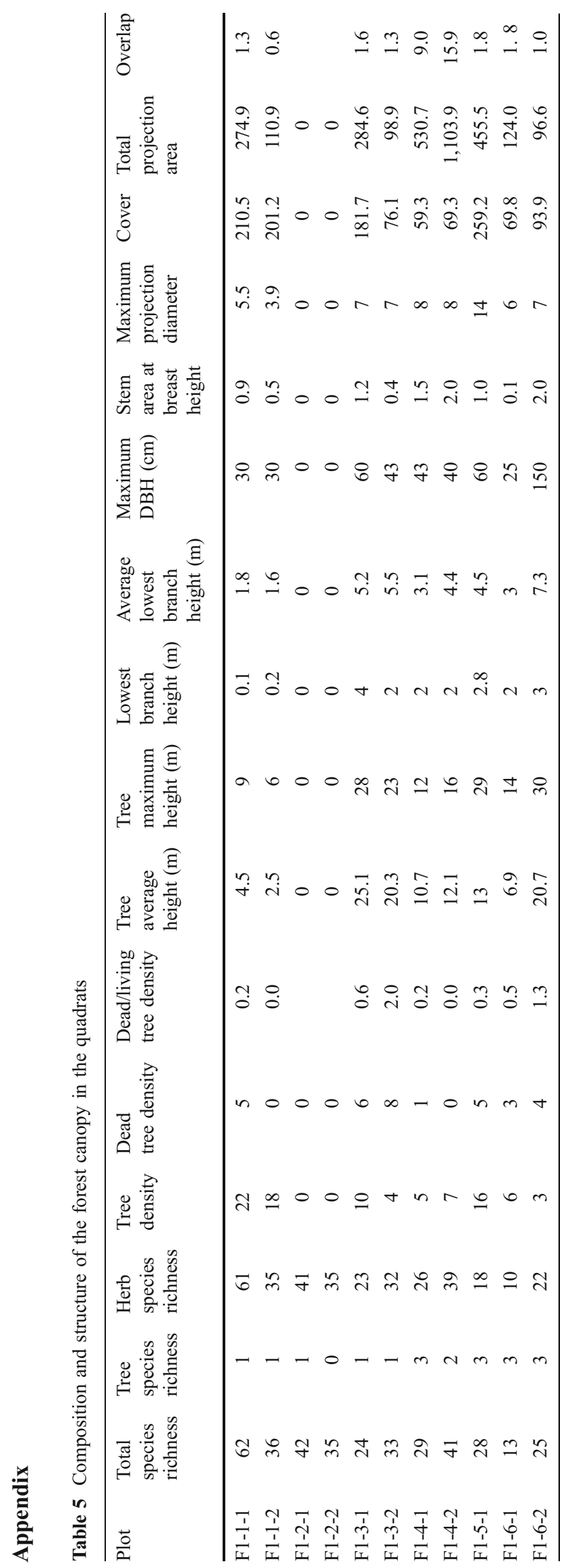




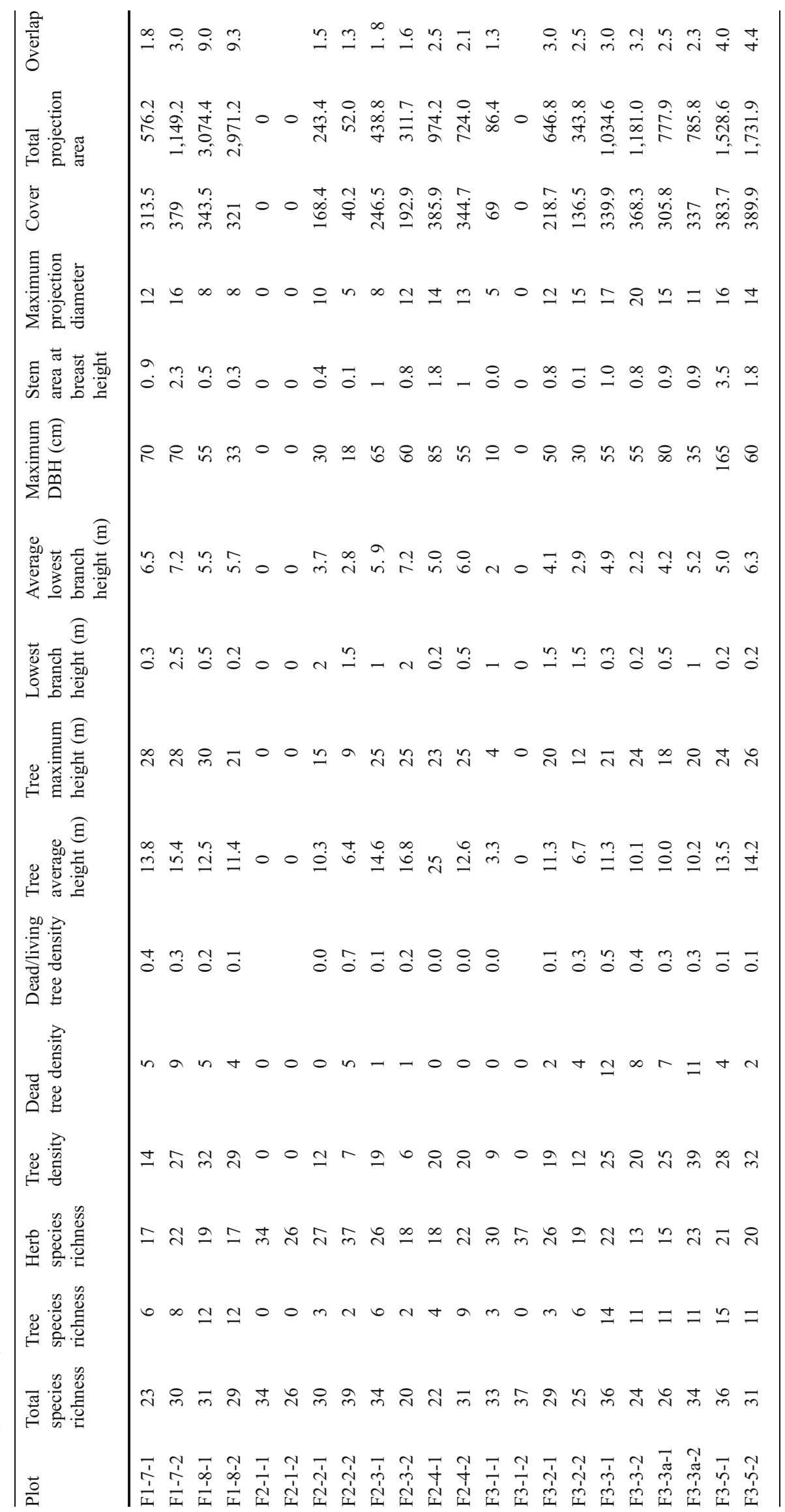




\section{References}

David AK (1998) Influence of leaf size on tree architecture: first branch height and crown dimensions in tropical rain forest trees. Trees 12:438-445

Fredericksen TS, Ross BD, Hoffman W, Morrison M, Beyea J, Johnson BN, Lester MB, Ross E (1999) Short-term understory plant community responses to timber-harvesting intensity on nonindustrial private forestlands in Pennsylvania. For Ecol Manage 116:129-139

George LO, Bazzaz F (1999) The fern understory as an ecological filter: emergence and establishment of canopy-tree seedlings. Ecology 80:833-845

Gillet F, Murisier B, Buttler A, Gallandat J-D, Gobat J-M (1999) Influence of tree cover on the diversity of herbaceous communities in subalpine wooded pastures. Appl Veg Sci 2:47-54

Hu JC, Schaller GB, Pan WS (1985) The giant pandas of Wolong. Sichuan Scientific \&Technological Press, Chengdu, p 298

Hu JC, Zhou A, Wei Y (1994) Food habits and feeding behaviour in Mabian Dafengding Nature Reserve (in Chinese). Journal of Sichuan Teachers College (Natural Science) 15:44-51

Kleinhenz V, Millne J, Walsh KB, Midmore DJ (2003) A case study on the effects of irrigation and fertilization on soil water and soil nutrient status, and on growth and yield of bamboo (Phyllostachys pubescens) shoots. Journal of Bamboo and Rattan 2:281-293

Li ZH, Denich M (2001) Community features of Indocalamus wilsoni in the Shenlongjia National Nature Reserve. J For Research (In Chinese) 12:169-175

Linderman M, Liu J, Qi J, An L, Ouyang Z, Yang J, Tan Y (2004) Using artificial neural networks to map the spatial distribution of understorey bamboo from remote sensing data. Int J Remote Sens 25:1685-1700

Linderman M, Scott B, Li A, Tan Y-C, Ouyang Z, Liu J (2005) The effects of understory bamboo on broad-scale estimates of giant panda habitat. Biol Conserv 121:383-390

Liu J, Ouyang Z, Yang Z, Taylor W, Groop R, Tan Y, Zhang H (1999) A framework for evaluating the effects of human factors on wildlife habitat: the case of giant pandas. Conserv Biol 13:1360 1370

Lourens P, Laurent B, Frans B (2006) Architecture of 54 moist-forest tree species: traits, trade-offs, and functional groups. Ecology 87:1289-1301

McKenzie D, Halpern CB, Nelson CR (2000) Overstory influences on herb and shrub communities in mature forests of western Washington. USA Can J For Res 30:1655-1666

Narukawa Y, Yamamoto S (2002) Effects of dwarf bamboo (Sasa sp.) and forest floor microsites on conifer seedling recruitment in a subalpine forest. Japan For Ecol Manage 163:61-70

Oksanen J. 2008. Multivariate analysis of ecological communities in $\mathrm{R}$ : vegan tutorial. available from http://www.probability.ca/cran/ web/packages/vegan/vegan.pdf

Pan W, Gao Z, Lu Z, Xia Z, Zhang M, Ma L, Meng G, Zhe X, Liu X, Cui H, Chen F (1988) The giant panda's natural refuge in the Qinling Mountains. Beijing University Press, Beijing, p 245
Qin ZS, Taylor AH, Cai XS (1993) The successional dynamics of bamboo and forests in giant panda environments in Wolong (in Chinese). China Forestry, Beijing, p 432

Ren Y (1998) Plants of giant panda habitats in the Qinling Mountains (in Chinese). Shaanxi Science and Technology Press, Xi'an, China, p 488

Schaller GB, Hu J, Pan W, Zhu J (1985) The giant pandas of Wolong. Chicago University Press, Chicago, p 318

State Forestry Administration PRC (2006) The 3rd national survey report on giant panda in China. Science, Beijing, p 355

Taylor AH, Huang JY, Zhou SQ (2004) Canopy tree development and undergrowth bamboo dynamics in old-growth Abies-Betula forests in southwestern China: a 12-year study. For Ecol Manage 200:347-360

Taylor AH, Qin Z (1988) Regeneration patterns in oldgrowth AbiesBetula forests in the Wolong natural reserve, Sichuan. China J Ecol 76:1204-1218

Taylor AH, Reid DC, Qin Z, Hu J (1991) Spatial patterns and environmental associates of bamboo (Bashania fangiana $\mathrm{Yi}$ ) after mass-flowering in southwestern China. B Torrey Bot Club 118:247-254

Toko S, Atsushi K, Yoshio I (2005) Effects of slope and canopy trees on light conditions and biomass of dwarf bamboo under a coppice canopy. J For Res 10:151-156

Wang W, Franklin SB, Ren Y, Ouellette JR (2006) Growth of bamboo $F$. qinlingensis and regeneration of trees in a mixed hardwoodconifer forest in the Qinling Mountains. China For Ecol Manage 234:107-115

Wang W, Franklin SB, Ouellette JR (2007) Clonal regeneration of an arrow bamboo, Fargesia qinlingensis, following giant panda herbivory. Plant Ecol 192:97-106

Wei FW, Zhou A, Hu JC (1996) Habitat selection by the giant panda in Mabian Defengding Nature Reserve. Acta Theriologica Sinica 16:2441-2445

Wei FW, Feng ZJ, Wang ZW, Liu JX (1999) Association between environmental factors and growth of bamboo species Bashania sp anostachya, the food of giant and red pandas (in Chinese). Acta Ecologica Sinica 19:710-714

Yang XZ, Meng SJ, Yong YG (1998) A study on the environment and ecology of Giant Panda in Foping(II): the Selection of Summer Habitat (in Chinese). Journal of Northwest University (Natural Science Edition) 28:348-353

Zhang ZJ, Hu JC (2000) A study on giant panda habitat selection (in Chinese). Journal of Sichuan Teachers College (Natural Science) $21: 18-21$

Zhang ZJ, Hu JC, Wu H (2002) Comparison of habitat selection of giant pandas and red pandas in the Qionglai mountains. Acta Theriologica Sinica 22:161-168

Zhang ZJ, Wei FW, Li M (2004) Microhabitat separation during winter among sympatric giant pandas, red pandas and tufted deer: the effects of diet, body size, and energy metabolism. Can J Zool 82:1451-1458

Zhang ZJ, Wei FW, Li M (2006) Winter microhabitat separation between giant and red pandas in Bashania faberi bamboo forest in Fengtongzhai Nature Reserve. J Wildl Manage 70:231-235 